http://jmscr.igmpublication.org/home/

ISSN (e)-2347-176x ISSN (p) 2455-0450

crossref DOI: https://dx.doi.org/10.18535/jmscr/v8i2.116

Journal Of Medical Science And Clinical Research

\title{
Gingival Overgrowth Resulting From Endodontic Flare-Up: Report of Two
}

\section{Cases}

Authors

\author{
Dr Amrita Samanta ${ }^{1}$, Dr Nandan Rudra Paul ${ }^{2}$ \\ ${ }^{1}$ Assistant Professor, Department of Oral Pathology, NSVK Sri Venkateshwara Dental College \& Hospital, \\ Bangalore, Karnataka, India \\ ${ }^{2}$ Assistant Professor, Department of Oral \& Maxillofacial Surgery, The Oxford Dental College \& Hospital, \\ Bangalore, Karnataka, India \\ *Corresponding Author \\ Dr Amrita Samanta
}

\begin{abstract}
Gingiva is the common clinical site for various oral lesions. Mostly, they present as gingival growth and are reactive in nature. Endodontic flare-up occur following endodontic treatment and is a significant problem, requiring unscheduled visit to the doctor. A list of risk factors are involved in such flare ups which ultimately could contribute to endodontic failures. Histopathology is a gold standard in the diagnosis of pathologies and must be included for any kind of suspicious lesions. This case report presents two rare cases where gingival overgrowths has occurred following endodontic treatments, which required scrupulous investigation and meticulous treatment.

Keywords: Gingiva, overgrowth, endodontic flare-up, sealant, periapical granuloma.
\end{abstract}

\section{Introduction}

In gingival overgrowths or enlargement the gingiva increases in size above its normal appearance. Gingival overgrowths are a common clinical presentation in everyday practice. They present as a myriad of pathologies and are responses to various stimuli. They could be localized or generalised tissue responses. The possible etiology may be attributed to dental plaque, foreign materials, hormonal imbalances, or systemic-induced manifestation. These enlarged gingival could always hinder the routine oral hygiene and invariably affects mastication, esthetics and speech. ${ }^{[1,2]}$

Endodontic treatment is brought about by biomechanically preparing the infected root canal (cleaning, shaping and disinfection) and obtaining a hermetic seal that will in turn aid in healing the periapical and periradicular tissue without causing any discomfort to the patient. ${ }^{[3]}$ However, endodontic flare up might occur post-treatment in some cases. Flare-up presents as swelling, erythema and/or pain involving the gingiva, mucosa and associated soft tissues of the endodontically treated tooth, and occur within a few hours or days following the treatment. ${ }^{[4]}$

\section{Case Report}

A male patient aged 36 years reported at our clinic OPD with a complaint of swelling in the upper anterior part of his mouth since two months. The patient's past dental history revealed that he had undergone endodontic treatment of teeth number 11,12,21,22 along with Porcelain fused metal 
crowns 2 years back and was without any significant medical history. Intraoral clinical examination revealed solitary, discrete, reddish gingival growth on the anterior maxilla on the right side. The growth was extending from the interdental papilla of 11,12 till the mucogingival junction and the patient had a fixed partial denture with porcelain fused to metal crowns in relation to $11,12,21,22$. The growth was soft on palpation and bleeding on probing was present. An Orthopantomograph confirmed the presence of radiolucency extending from the crestal bone of endodontically treated teeth 11,12 and extending till the apex of 12 and a small breach in root continuity of tooth no.12. The patient was explained about the surgical intervenation. Following this, the porcelain fused to metal crown was removed from 12 . A broad-based mucoperiosteal flap was raised extending from mesial aspect of 11 upto the mesial surface of 13 , exposing the roots of 11,12 as the overlying bone of 11,12 was completely resorbed.. The surgical site revealed alveolar bone resorption, root resoption at the apical and middle third of 12 , and soft tissue mass that extended from root end of 12 upto the overlying gingiva. The soft tissue mass and the gingival growth was excised and sent for histopathological examination, 12 was extracted and the site was curetted and irrigated profusely. The defect was filledwith allogenic bone graft (Hydroxyappetite $+\beta$ - Tri Calcium Phosphate) and covered with Allogenic collagen sheet secured with 4-0 vicryl suture. Patient was advised about the oral hygiene protocol and adviced follow up after 3, 7, 15 days. The graft was nicely taken without any complications, however, the site was irrigated on every visit.

Meanwhile, the histopathology revealed the presence of hyperplastic, thin epithelium. The connective tissue revealed extensive proliferation of plump endothelial cells and presence of many tiny vascular channels, surrounded by numerous proliferative fibroblasts, and delicate collagen fibrils. There were dense inflammatory infiltrate composed of lymphocytes, plasma cells and some macrophages. Few clusters of hemosiderin deposits and cholesterol clefts were present. Thus, a diagnosis of periapical granuloma was established. Further follow ups were done after 1, 3, 5 months and the surgical site was found to have healed completely. This case suggests the occurrence of extra osseous gingival granuloma secondary to peri apical granuloma from an endodontic flare up.

In another case, a male patient aged 56 years, without any significant medical history, reported at our clinic OPD with a nodular, pale pink, smooth surfaced gingival mass on the lingual surface of left posterior mandible. The growth appeared lingual to 37,just above the floor of oral cavity which was round in shape and $0.5 \times 0.5 \mathrm{~mm}$ in size. The tooth was endodontically treated 3 years back with metal crown. On palpation, the growth was soft to feel and bled on probing. The Intra oral peri apical radiograph revealed apical bone resorption and a radiolucent lesion extending from the distal alveolar crest to the root apices of 37 and one distal root canal which was not obturated. During surgery under local anaesthesia, the tooth was extracted, the socket was curretaged to pull out a thick epithelium lined fistulous tract and the lingual swelling was excised. The abnormal tissue growth and the fistulous tract was sent for histopathological examination.

Histopathology suggests presence of thin, atrophic epithelium with elongated rete ridges. The connective tissue revealed extensive neoangiogenesis with plump endothelial cells and endothelial budding. There were many fibroblasts and inflammatory cells comprising of lymphocytes and plasma cells were in abundance. Few cholesterol clefts were also present. Thus, pointing towards a diagnosis of periapical granuloma.

In fact, there was again an occurance of extrosseous gingival granuloma extending from a periapical granuloma, resulting due to endodontic flareup. 


\section{JMSCR VoI||08||Issue||02||Page 674-678||February}
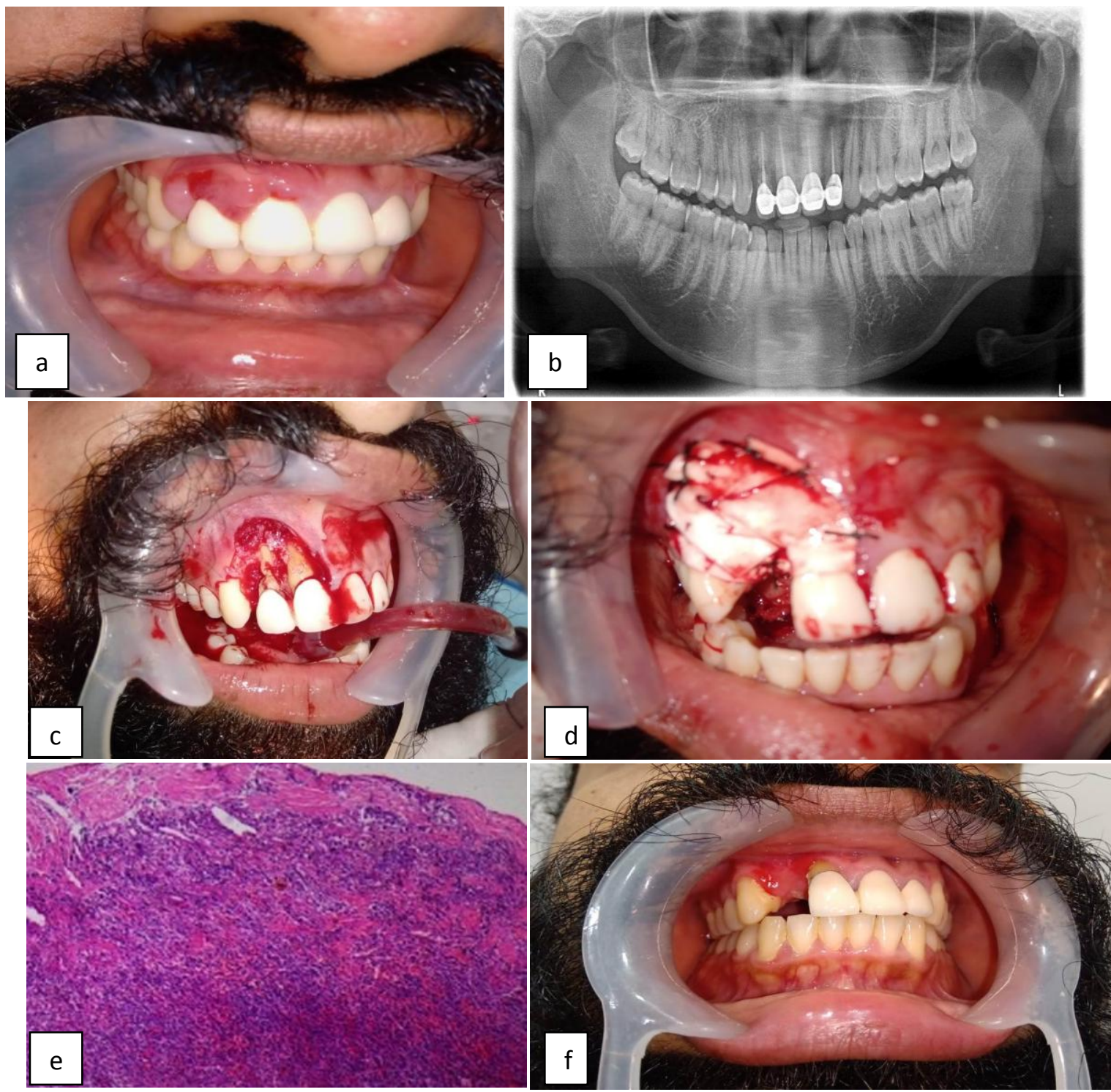

Figure 1: (a) Pre-op clinical photograph of gingival growth; (b) Orthopantomograph showing radiolucency and breach of root continuity of tooth no. 12; (c) Intra-op photograph showing mid root resorption of tooth no.12 and complete resorption of labial alveolar bone of tooth no. 11, 12. (d) Bone grafting done and secured with collagen graft on the defect; (e) Histopathological features suggestive of periapical granuloma; (f) 2 months post-op photograph showing proper healing of surgical site with mild gingival recession of tooth no. 11 .

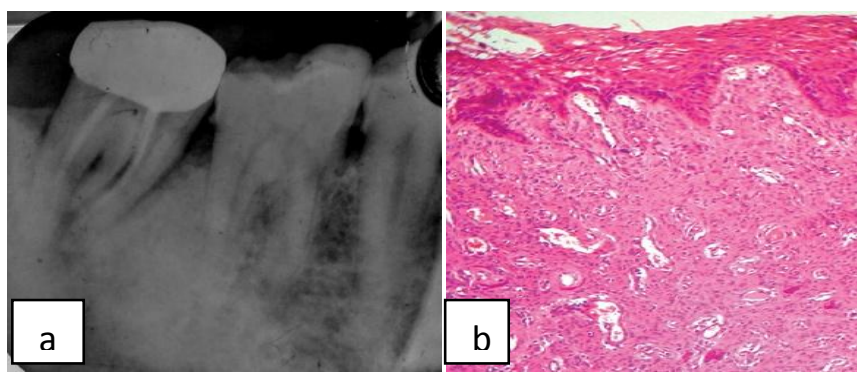

Figure 2: (a) Intraoral periapical radiograph shows a hollow mesial root canal, periapical radiolucency and a sinus tract in tooth no 37; (b)Histopatholoogical features are suggestive of periapical granuloma.

\section{Discussion}

Gingiva is the common site for occurence of reactive tissue growths in response to chronic low- grade irritation, underlying systemic disease, drug-induced stimulus, local iatrogenic factors, and oral microbiota. ${ }^{[1,5]}$ They appear clinically as 
smooth-surfaced, pedunculated or sessile masses, varies from pink to red in colour and soft to firm in consistency. However, their clinical appearances resemble to that of neoplasms, which may cause some diagnostic dilemmas. ${ }^{[6]}$ Proper investigation to find out the etiologic factors and accuracy of diagnosis helps in appropriate management of the lesion. A detailed medical and dental history is a vital adjunct for the judicious treatment of such lesions. ${ }^{[2]}$ Endodontic flare- ups are multifactorial outcomes of endodontic treatment which are undesirable, requiring an unscheduled revisit and causes great discomfort to patient due to pain and swelling. ${ }^{[7]}$ Various factors determine the occurance of endodontic flare-ups, which include: treatment sessions; intracanal medications; gender, age, and dental group of the patient; presence of preoperative pain / swelling; pulpal and periradicular diagnosis; initial or retreatment; presence of root canal irritants; apical extrusion of irritants/debris; apical patency. ${ }^{[8]}$ In our present cases, the endodontic flare-up was, in fact, a chronic irritation to the periradicular tissue. This kind low grade irritation for a longer time, led to the occurrence of periapical granuloma. The periapical granuloma has in turn dissolved the overlying alveolar bone and resulted in the form of discrete, localised gingival growth. Both our cases signify a rare outcome of an endodontic flare up which was actually due to percolation of sealant in first case from a breach in the root and in second case the apical irritation was from bacterial growth in the empty distal root canal which was not obturated. Furthermore, microleakage of sealants or restorative material has been shown to be adverse to the endodontic treatment. ${ }^{[9]}$ The histopathology of both our cases showed hyperplastic / atrophic, thin epithelium. There were endothelial proliferation leading to neovascularisation, fibroblastic proliferation as well as inflammatory cell infiltrate. These findings led to the diagnosis of periapical granuloma. Periapical granuloma, histologically, is comprised of granulation tissue, which exhibits proliferation of endothelial cells and fibroblasts, with variable number of inflammatory cells. The inflammatory process coupled with local increase in vascularity of tissue leads to resorption of the supporting bone. ${ }^{[10,11]}$ In both our cases, the long standing reactive pathology had the potential to dissolve the overlying alveolar bone and present itself clinically as a gingival growth, which is rare and enigmatic.

\section{Conclusion}

The clinical presentation of the gingival lesions can be quite similar. Thus, it is imperative to investigate the etiology of such lesions for prudent diagnosis and judicious treatment. Our cases actually represented that disease process can even be lodged well beyond the gingiva.

\section{References}

1. Banerjee S, Pal TK. Localized Gingival Overgrowths: A Report of Six Cases. Contemp Clin Dent.2017 Oct-Dec; 8(4): 667-671.

2. Raizada S, Varghese JM, Bhat KM, Gupta K. Isolated gingival overgrowths: A review of case series. Contemp Clin Dent. 2016 Apr-Jun; 7(2): 265-268.

3. Sipavičiūtè E, Manelienè R. Pain and fl are-up after endodontic treatment procedures. Stomatologija, Baltic Dental and Maxillofacial Journal. 2014; 16:25-30.

4. Priyanka.SR,Veronica Dr. Flare-Ups in Endodontics - A Review. IOSR Journal of Dental and Medical Sciences. 2013 SepOct; 9 (4):26-31.

5. Rossmann JA. Reactive Lesions of the Gingiva: Diagnosis and Treatment Options. The Open Pathology Journal. 201; 5: 23-32.

6. Mortazavi H, Safi $Y$, Baharvand $M$, Rahmani S, Jafari S. Peripheral Exophytic Oral Lesions: A Clinical Decision Tree. Hindawi International Journal of Dentistry. 2017. Article ID 9193831. 19 page.

7. Nair M, Rahul J, Devadathan A, Mathew J. Incidence of endodontic flare-ups and its 
related factors: A retrospective study. J Int Soc Prevent Communit Dent 2017;7:1759.

8. Onay EO, Ungor M, Yazici AC. The evaluation of endodontic flare-ups and their relationship to various risk factors. BMC Oral Health 2015; 15:142.

9. Daokar S, Kalekar A. Endodontic FailuresA Review. IOSR Journal of Dental and Medical Sciences (IOSR-JDMS) 2013 JanFeb;4(5):05-10.

10. Regezi JA, Sciubba JJ, Jordan RCK. Oral Pathology Clinical Pathologic Correlations $6^{\text {th }}$ ed. Elsevier: 2013; pp. 317-8.

11. Rajendran R, Sivapathasundaram B. Shafer's Textbook of Oral Pathology. $5^{\text {th }}$ ed. Elsevier 2006; pp. 398-403. 